\title{
Regulation of Neurokine Receptor Signaling and Trafficking
}

\author{
Neil M. Nathanson * \\ Department of Pharmacology, Box 357750, University of Washington, Seattle, WA 98195-7750
}

\begin{abstract}
Leukemia inhibitory factor (LIF) and ciliary neurotrophic factor (CNTF) are neurally active cytokines, or neurokines. LIF signals through a receptor consisting of gp130 and the low affinity LIF receptor (LIFR), while the CNTF receptor consists of gp130, LIFR, and the low affinity CNTF receptor (CNTFR). Ser1044 of the LIFR is phosphorylated by Erk1/2 MAP kinase. Stimulation of neural cells with growth factors which strongly activate Erk1/2 decreases LIFmediated signal transduction due to increased degradation of the LIFR as a consequence of Erk1/2-dependent phosphorylation of the receptor at Ser1044.

The gp130 receptor subunit is phosphorylated, at least in part by calmodulin-dependent protein kinase II, at Ser782, which is adjacent to a dileucine internalization motif. Ser782 appears to negatively regulate cytokine receptor expression, as mutagenesis of Ser782 reseults in increased gp130 expression and cytokine-induced neuropeptide gene transcription.
\end{abstract}

The LIFR and gp130 are transmembrane proteins, while CNTFR is a peripheral membrane protein attached to the cell surface via a glycosylphosphatidylinositol tail. In unstimulated cells, CNTFR but not LIFR and gp130 is localized to detergent-resistant lipid rafts. Stimulation of cells with CNTFR causes translocation of LIFR and gp130 into the lipid rafts, while stimulation with LIF does not induce receptor translocation, raising the possibility that CNTF could induce different patterns of signaling and/or receptor trafficking than caused by LIF.

We used a compartmentalized culture system to examine the mechanisms for retrograde signaling by LIF and CNTF from distal neurites to the cell bodies of mouse sympathetic neurons. Stimulation with neurokines of the distal neurites of sympathetic neurons grown in a compartmentalized culture system resulted in the activation and nuclear translocation of the transcription factor Stat3. Retrograde signaling required Jak kinase activity in the cell body but not the distal neurites, and could be blocked by inhibitors of microtubule but not microfilament function. The results are consistent with a signaling endosomes model in which the ctyokine/ receptor/Jak kinase complex is transported back to the cell body where Stat 3 is activated. While both LIF and CNTF mediate retrograde activation of Stat3, the kinetics for retrograde signaling differ for the two neurokines.

\section{Keywords}

cytokine; retrograde signaling; neurotrophic factor; signal transduction

\footnotetext{
(C) 2012 Elsevier Ltd. All rights reserved.

*nathanso@u.washington.edu, Tel: 206-543-9457, Fax: 206-616-4230.
}

Publisher's Disclaimer: This is a PDF file of an unedited manuscript that has been accepted for publication. As a service to our customers we are providing this early version of the manuscript. The manuscript will undergo copyediting, typesetting, and review of the resulting proof before it is published in its final citable form. Please note that during the production process errors may be discovered which could affect the content, and all legal disclaimers that apply to the journal pertain. 


\section{Introduction}

Leukemia inhibitory factor (LIF) and ciliary neurotrophic factor (CNTF) are members of a family of structurally related pluripotent cytokines that have diverse effects on many types of cells and tissues and which can regulate both neuronal survival and phenotypic expression of neuropeptides and neurotransmitters. In addition to CNTF and LIF, this subfamily of neuropoietic cytokines, or neurokines, includes the interleukins IL-6, IL-11, IL-27, IL-37, oncostatin $\mathrm{M}$, and cardiotrophin-1, and bind to an overlapping set of receptor polypeptides (Stahl and Yancopoulos, 1993; Trouillas et al., 2009; Wang et al., 2009). CNTF was identified by its ability to increase the survival of chick ciliary neurons in culture (Barbin et al., 1984). It is expressed primarily in glial cells of both the peripheral and central nervous systems (Stöckli et al., 1989). LIF was independently identified by a number of different groups investigating many diverse actions; the first evidence that LIF could act in the nervous system came from the demonstration that LIF is secreted by cultured heart cells and can switch sympathetic neurons from an adrenergic to a cholinergic phenotype (Yamamori et al., 1989).

The neurokine receptors are structurally similar and share overlapping polypeptide components (for reviews, see Taga and Kishimoto, 1997; Han et al., 2006; Baker et al., 2007; Trouillas et al., 2009; Wang et al., 2009). A "low affinity" or "alpha" IL-6 receptor (IL-6R) was the first neurokine receptor to be identified, and was shown to associate with an additional transmembrane component, gp130, to yield a high-affinity functionally active receptor (reviewed in Taga and Kishimoto, 1997). Similarly, low affinity alpha receptor subunits for CNTF and LIF were subsequently identified, and were also shown to require gp130 for functional responsiveness (Gearing et al., 1992; Stahl et al., 1993). The LIFR, IL-6R, and gp130 are all transmembrane proteins, although a soluble IL-6R which lacks the transmembrane and cytoplasmic domains can still associate with gp130 to form a functional receptor. The CNTFR lacks a transmembrane domain but is associated with the membrane via a glycosylphosphatidylinositol tail; however, a soluble CNTFR lacking this tail can also form a functional receptor complex (Davis et al., 1993). In the presence of ligand, the monomeric subunits associate to form the functional receptor complexes: LIF induces the formation of a heterodimeric receptor (LIFR plus gp130), and CNTF also induces the formation of a heteromultimeric receptor (LIFR plus gp130 plus CNTFR; Taga and Kishimoto, 1997). Thus, while the low affinity IL-6R and CNTFR confer specificity for their respective ligands, the receptor signalling subunits which mediate the action of IL-6 are two gp130s acting as a homodimer, and the receptor signalling subunits which mediate the action of both CNTF and LIF are LIFR plus gp130 acting as a heterodimer.

The neurokines have many actions in the nervous system. Both CNTF and LIF will induce the expression of choline acetyltransferase (ChAT) and neuropeptide genes in cultured sympathetic neurons, and depress the expression of tyrosine hydroxylase (Sadaat et al., 1989; Fann and Patterson, 1994). LIF and CNTF promote the survival of sensory, ciliary, and central neurons, promote survival and maturation of cultured oligodendrocytes, and induce the differentiation of O-2A glial progenitors into type-II astrocytes in vitro (Bonni et al., 1997). CNTF in vivo induces sprouting and prevents developmentally-induced death of motor neurons (Gurney et al., 1992) and axotomy-induced death of motor and other central neurons (Clatterbuck et al., 1993). While loss of CNTF has only modest effects on postnatal survival of a population of motor neurons and lack of LIF has no significant effect on motoneuron survival, a double knockout lacking both LIF and CNTF results in a pronounced decrease in motoneuron survival and function (Sendtner et al., 1996). Administration of LIF or CNTF delays the withdrawal of polyneuronal innervation at the neuromuscular junction, and LIF gene disruption results in an increase in the rate of loss of polyneuronal innervation and reduces regeneration of skeletal muscle following damage 
(Kwon et al., 1995; Kurek et al., 1997). LIF-deficient mice exhibit impaired regeneration of sensory neurons after injury and impaired neurogenesis in the olfactory epithelium after olfactory bulbectomy (Cafferty et al., 2001; Bauer et al., 2003). CNTF-deficient mice do not exhibit the motoneuron sprouting that normally occurs after partial denervation (Siegel et al., 2000), and exhibit decreased glial cell survival in a demyelinating disease model (Linker et al., 2002). Because the LIFR and gp130 receptor subunits are components of the functional receptors for multiple cytokines, inactivation of the genes encoding the cytokine receptors have more severe phenotypes than disruption of individual cytokine genes. Disruption of gp130 results in embryonic lethality, with decreased number of numbers of sensory and motor neurons found in knockout embryos (Nakashima et al., 1999). Disruption of the LIFR or CNTFR results in perinatal lethality with a significant loss of motoneurons (Li et al., 1995; DeChiara et al., 1995; Ware et al., 1995). Even LIFR +/- heterozygotes show a decreased number of forebrain neural stem cells (Shimazaki et al., 2001). Interestingly, compound heterozygotes containing only one LIFR allele and only a truncated gp130 allele also exhibit, like the CNTF -/- mice, increased severity in a demyelinating disease model (Butzkueven et al., 2002).

The cytoplasmic domains of LIFR and gp130 do not contain any tyrosine kinases or other enzymatic domains. The JAK-family tyrosine kinases Jak1, Jak2, and Tyk2 are constitutively associated with gp130 and LIFR and are activated by tyrosine phosphorylation in response to neurokines (Haan et al., 2006). Gene knockout experiments indicate that Jak1 but not Jak2 is absolutely required for LIF and CNTF action in both neural and nonneuronal cells (Rodig et al., 1998; Parganas et al., 1998).

There are multiple signal transduction pathways which are downstream of tyrosine kinase activation. JAK family kinases phosphorylate and activate the STAT family of transcription factors, which interact either with the receptor subunits themselves or with Jaks and translocate to the nucleus following phosphorylation. The gp130-family cytokines preferentially activate Stat 3 but can also activate Stat1 and Stat5. LIF and related neurokines can cause cell-type specific activation of the mitogen-activated protein (MAP) kinase cascade. In addition, a variety of other signaling pathways can also be activated following cytokine stimulation (Baker et al., 2007; Trouillas et al., 2009).

\section{Regulation of LIF receptor expression and signaling by heterologous receptor activation}

Our laboratory used fusion proteins containing the cytoplasmic domain of the LIFR to show that extracts from LIF-stimulated cells could induce LIFR phosphorylation (Scheimann et al., 1995). Cell fractionation experiments demonstrated that Erk1 and Erk2 MAP kinases mediated this phosphorylation, and site-directed mutagenesis identified Ser1044 as the sole phosphorylation site. We used chimeric receptors containing the cytoplasmic domain of the LIFR to determine the role of Ser1044 in the regulation of cytokine receptor signaling. Insulin stimulation of hepatoma cells attenuated LIFR-induced gene induction. This negative regulation of LIFR signaling was lost in LIFR mutants lacking Ser1044. Subsequent studies showed that phosphorylation of Ser1044 by MAPK after growth factor stimulation of a variety of neon-neuronal cells led to increased degradation of the LIFR (Blanchard et al., 2000). Thus, MAPK-mediated phosphorylation of LIFR at Ser1044 regulates LIFR signaling in response to heterologous receptor activation.

Because signaling and regulatory pathways can be cell type-specific, we examined the effects of growth factor stimulation of neuronal cells on LIF-mediated signal transduction (Port et al., 2008). Treatment of NBFL neuroblastoma cells with either epidermal growth factor (EGF) or fibroblast growth factor (FGF), factors which cause robust and prolonged 
activation of MAPK, led to significant decreases in the levels of LIFR but not gp130. In contrast, treatment of NBFL cells with LIF, CNTF, oncostatin M, or nerve growth factor caused only modest and transient activation of MAPK and did not significantly decrease LIFR levels. The EGF-mediated decrease in LIFR resulted from an increased rate of LIFR degradation by a lysosomal pathway. The decrease in LIFR levels and increase in its rate of degradation could be blocked by inhibition of the Erk1/2 MAPK pathway.

These decreases in LIFR expression were accompanied by changes in LIF- mediated signaling. EGF pretreatment caused a significant decrease in the ability of LIF to stimulate tyrosine phosphorylation of Stat3; this inhibition by EGF was also dependent on activation of the MAPK pathway. We again used chimeric receptors containing the intracellular domain of the LIFR to determine the role of Ser1044 in the regulation of LIF-mediated signaling. Pretreatment with EGF inhibited gene induction mediated by chimeric receptors containing the wildtype LIFR cytoplasmic domain but did not inhibit signaling by receptors lacking Ser1044.

Neurons are exposed in vivo to different combinations of cytokines and growths during development and in response to various physiological and pathological conditions. The MAPK pathway can be activated not only by receptor tyrosine kinases but also by G-protein coupled receptors. The regulation of LIFR expression and LIF-mediated signal transduction by Erk1/2 MAPK represents a potential mechanism for cross-talk between cytokines with growth factor, neurotransmitter, and hormone signaling pathways.

\section{Regulation of gp130 expression by serine phosphorylation}

Incubation of fusion proteins containing the cytoplasmic domain of gp130 with 3T3-L1 cell extracts from LIF- or growth factor-stimulated cells led to gp130 phosphorylation (Gibson et al., 2000). Because site-directed mutagenesis did not yield an unambiguous identification of the phosphorylation site(s), we used Edman's degradation and mass spectroscopy to identify Ser782 as the sole site of phosphorylation. Interestingly, Ser780 was not phosphorylated but was required for phosphorylation of Ser782. Ser782 is located adjacent to a dileucine motif which was previously shown to regulate internalization of gp130 (Dittrich et al., 1996). Chimeric receptors containing the cytoplasmic domain of gp130 lacking Ser782 were expressed at higher levels than chimeric receptors containing the wildtype gp130 sequence. Expression of the chimeric receptors lacking Ser872 in neuroblastoma cells lead to greater increases in neuropeptide reporter gene expression compared to expression of wildtype type receptors. Thus, Ser782 appears to regulate expression and signaling of the gp130 receptor subunit.

Unlike the MAPK-mediated phosphorylation of LIFR, the phosphorylation of Ser782 of gp130 was not mediated by MAPK. The phosphorylation site resembles a consensus phosphorylation site for calmodulin dependent protein kinase II (CaMKII), and incubation of stimulated 3T30-L1 extracts with a highly specific CamKII peptide inhibitor significantly decreased gp130 phosphorylation at Ser782 (Gibson et al., 2005). Purified CamKII could phosphorylate gp130 at Ser782, and antibodies against both CaMKII and CamKIV could remove the gp130-targeted kinase from stimulated 3T3-L1 cell extracts. Interestingly, pretreatment of cells with inhibitors of the MAPK pathway blocked subsequent stimulation of Ser782 phosphorylation activity, but the inhibitors did not block Ser782 phosphorylation due to direct incubation with LIF-stimulated cell lysates. These results indicate that CaMKII and perhaps CaMKIV phosphorylate Ser782 to regulate gp130 internalization and subsequent signaling, and this phosphorylation requires activation of the MAPK pathway. Interestingly, LIF has been shown to cause activation of CaMKII and CaMKIV in cardiac 
myocytes due to MAPK-mediated phosphorylation and activation of L-type calcium channels (Kato et al., 2000; Takahashi et al., 2004).

The work of Gibson et al. (2005) also indicated that there were additional kinases that could phosphorylates gp130 at Ser782. Recently, Radtke et al. (2010) reported that treatment of HepG2 cells with inflammatory cytokines such as interleukin- $1 \beta$ and tumor necrosis factor a resulted in phosphorylation of gp130 at Ser 130 by MAPK-activated protein kinase 2. This phosphorylation also resulted in increased internalization and subsequent degradation of gp130, resulting in decreased Il-6 signaling. Thus, multiple protein kinases can led to cytokine- and growth factor- induced phosphorylation and subsequent regulation of gp130 expression and function.

\section{Differential localization of neurokine receptor subunits in lipid rafts}

The LIFR and gp130 are both single transmembrane domain polypeptides, with the amino termini located on the extracellular side and the carboxyl termini on the intracellular side of the membrane. In contrast, the CNTFR is located extracellularly and is attached to the plasma membrane by a glycosylphosphatidylinositol (GPI) tail (Wang et al., 2009). GPIlinked proteins are frequently localized to lipid rafts (Lucero and Gibbons, 2004). Lipid rafts are microdomains of the cell membrane which are enriched in cholesterol, sphingomyelin and glycosphingolipids and were originally characterized by their inability to be solubilized in certain non-ionic detergents. Lipid rafts contain distinct subsets of proteins and lipids and can thus create distinct environments for cell signaling (Simons and Ikonen, 1997; Simmons and Toomre, 2000: Pike, 2003). We found that in unstimulated IMR-32 neuroblastoma cells the CNTFR was found in detergent-resistant lipid rafts, while both gp130 or LIFR were found in non-raft membrane fractions. In addition, we found that stimulation of these cells with CNTF resulted in a rapid translocation of a portion of gp130 and LIFR into detergentresistant lipid rafts while stimulation with LIF did not induce receptor subunit translocation. Depletion of cholesterol disrupts lipid rafts and blocked the CNTF-induced translocation of LIFR and gp130. While cholesterol-depletion did not inhibit Stat3 activation in response to either CNTF or LIF, it strongly inhibited both CNTF- and LIF-mediated activation of Erk1/2 MAPK and Akt.

Previous work has shown a number of differences in the regulation of signaling by CNTF compared to LIF. For example, Rao et al. (1992) demonstrated that membrane depolarization blocked the induction of choline acetyltransferase and neuropeptide expression in response to LIF but not CNTF, and Johnson and Nathanson (1994) found that protein kinase $\mathrm{C}$ downregulation differentially affected CNTF and LIF signaling. In addition, as noted below, O'Brien and Nathanson (2007) found that the kinetics of retrograde signaling by CNTF and LIF were different. While this work did not detect a differential dependence on lipid rafts of LIF and CNTF signaling, these results do raise the possibility that LIF and CNTF could exhibit differential signaling due to the differential localization of their respective signaling receptors in lipid rafts. Because the pathways for endocytosis of membrane proteins localized to lipid rafts is usually distinct from that used by non-raft proteins, these results also raise the possibility that the receptors activated by LIF and CNTF might undergo endocytosis by different pathways or mechanisms.

\section{Retrograde cytokine signaling from distal neurites to the cell body}

\subsection{Introduction to retrograde signaling}

While the analysis of how growth factor and cytokine receptors regulate gene expression is comparatively straightforward for nonneuronal cells, the action of neurotrophic receptors require in addition an understanding of how stimulation of a surface receptor at the end of a 
neuronal process can lead to a retrograde signal transmitted over a long distance back to the cell body. While several different mechanisms have been proposed for how activation of a TrkA receptor by NGF at a distal neurite can result in signaling in the nucleus and resultant altered gene expression, and some inconsistencies remain in the literature, the majority of the evidence supports a "Signaling Endosome" model, in which the activated TrkA receptor undergoes endocytosis and is then retrogradely transported to the cell body where signals are initiated or propagated. Activation of a Trk receptor by NGF on a distal process results in endocytosis and retrograde transport of a "signaling endosome" containing NGF bound to TrkA, and activated Erk1/2, p38, and Akt (Ye et al., 2003; Delcroix et al., 2003; Yano and Chao, 2004, and Howe and Mobley, 2005). The transport of Trk receptors uses a microtubule-based system using dyenin as a motor (Heerssen et al., 2004). In hippocampal neurons, the neuron-specific dynein isoform IC-1B but not the ubiquitous IC-2C isoform transports signaling endosomes containing TrkB. In contrast, PC12 cells do not express IC-1B, and IC-2C transports TrkA-containing signaling endosomes (Ha et al., 2008). It is not known if this difference represents differences between TrkA and TrkB receptors, central neurons and peripheral neurons, or an artifact related to the transformed nature of PC12 cells.

\subsection{Retrograde signaling by LIF and CNTF}

Little information is available on the possible mechanisms involved in retrograde signaling by CNTF and LIF. LIF and CNTF undergo retrograde transport from distal process both in vivo and in cell culture (Hendry et al, 1992; Curtis et al., 1984; Ure and Campenot, 1994), and application of LIF to distal processes causes induction of ChAT expression in compartmentalized cultures of rat sympathetic neurons (Ure et al., 1992).

We used compartmentalized cultures of mouse sympathetic neurons to study the mechanisms of retrograde signaling by LIF and CNTF by measuring tyrosine phosphorylation and nuclear translocation of Stat3 using site-specific antibodies (O'Brien and Nathanson, 2007). Stimulation of distal neurites with LIF led to the appearance of nuclear phospho-Stat 3 after 2 hours. This retrograde signaling could be blocked by inhibitors of microtubule-based transport but not by inhibitors of microfilament-based transport. We used domain-specific inhibition of Jak kinase activity to show that Jak activity in the cell bodies was required for retrograde appearance of nuclear Stat3 after stimulation of distal neurites. Jak kinase activity in the distal neurites themselves was not required for retrograde signaling. These results indicate that transport of activated Stat 3 or activated Jak kinase from the neurites to the cell body is not required for retrograde signaling. These results are consistent with a signaling endosome model where the cytokine-receptor complex undergoes microtubule-based transport back to the cell bodies, where Jak activation and subsequent phosphorylation of Stat 3 occurs.

CNTF also induces the nuclear translocation of phospho-Stat 3 after stimulation of distal neurites, but retrograde signaling by CNTF occurs with a much more rapid time course than signaling by LIF. These results raise the possibility that the rate of endocytosis and/or rate of retrograde transport of activated cytokine receptors may be dependent on which cytokine is bound to the receptors. It is possible that this difference in kinetics is due to the cytokinedependent differential localization of receptor subunits in lipid rafts.

\section{Concluding remarks}

The results summarized here show that the cytokine receptor subunits gp130 and LIFR are substrates for phosphorylation by different protein kinases and that phosphorylation appears to regulate receptor trafficking and/or signaling. The role of these phosphorylation events in the regulation of cytokine receptors by physiological or pathophysiological signals in the 
intact nervous system is a topic that should be the subject of future investigations. In addition, the molecular and cellular mechanisms responsible for the different kinetics of retrograde signaling by LIF compared to CNTF remains to be determined.

Knowledge of the mechanisms for the regulation of cytokine receptor signaling are important for understanding both potential pathological consequences when their signaling is disrupted and in the development of potential therapeutic uses. LIF and CNTF are survival factors for motor neurons, and mice lacking either the CNTF receptor or both LIF and CNTF exhibit motor neuron deficits. Mutations which disrupt retrograde transport cause motor neuron degeneration, and alterations in retrograde transport have been shown to occur in ALS. Our results with sympathetic neurons indicate that there are both similarities and differences in the mechanism of retrograde signaling by LIF and CNTF. Elucidation of their mechanisms of retrograde signaling will provide valuable information both on the pathways involved in motor neuron survival and potential new targets for ALS therapy.

\section{Acknowledgments}

Research in the author's laboratory has been supported in part by the National Institutes of Health under grant NS30410.

\section{Abbreviations}

$\begin{array}{ll}\text { ALS } & \text { amyotrophic lateral sclerosis } \\ \text { CNTF } & \text { ciliary neurotrophic factor } \\ \text { CNTFR } & \text { CNTF receptor } \\ \text { GPI } & \text { glycosylphosphatidylinositol } \\ \text { IL } & \text { interleukin } \\ \text { IL-6R } & \text { interleukin-6 recepttor } \\ \text { LIF } & \text { leukemia inhibitory factor } \\ \text { LIFR } & \text { LIF receptor } \\ \text { MAPK } & \text { mitogen-activated protein kinase }\end{array}$

\section{References}

Baker SJ, Rane SG, Reddy EP. Hematopoietic cytokine receptor signaling. Oncogene 2007. 2007; 26:6724-6737.

Barbin G, Manthorpe M, Varon S. Purification of the chick eye ciliary neuronotrophic factor. J Neurochem. 1984; 43:1468-1478. [PubMed: 6491662]

Bauer S, Rasika S, Han J, Mauduit C, Raccurt M, Morel G, Jourdan F, Benahmed M, Moyse E, Patterson PH. Leukemia inhibitory factor is a key signal for injury-induced neurogenesis in the adult mouse olfactory epithelium. J Neurosci. 2003; 23:1792-1803. [PubMed: 12629183]

Blanchard F, Duplomb L, Wang Y, Robledo O, Kinzie E, Pitard V, Godard A, Jacques Y, Baumann H. Stimulation of leukemia inhibitory factor receptor degradation by extracellular signal-regulated kinase. J Biol Chem. 2000; 275:28793-28801. [PubMed: 10858440]

Bonni A, Sun Y, Nadal-Vicens M, Bhatt A, Frank DA, Rozovsky I, Stahl N, Yancopoulos GD, Greenberg ME. Regulation of gliogenesis in the central nervous system by the JAK-STAT signaling pathway. Science. 1997; 278:477-483. [PubMed: 9334309]

Butzkueven H, Zhang JG, Soilu-Hanninen M, Hochrein H, Chionh F, Shipham KA, Emery B, Turnley AM, Petratos S, Ernst M, Bartlett PF, Kilpatrick TJ. LIF receptor signaling limits immune-mediated 
demyelination by enhancing oligodendrocyte survival. Nat Med. 2002; 8:613-619. [PubMed: 12042813]

Cafferty WB, Gardiner NJ, Gavazzi I, Powell J, McMahon SB, Heath JK, Munson J, Cohen J, Thompson SW. Leukemia inhibitory factor determines the growth status of injured adult sensory neurons. J, Neurosci. 2001; 21:7161-7170. [PubMed: 11549727]

Clatterbuck RE, Price DL, Koliatsos VE. Ciliary neurotrophic factor prevents retrograde neuronal death in the adult central nervous system. Proc Natl Acad Sci USA. 1993; 90:2222-2226. [PubMed: 8460125]

Curtis R, Scherer SS, Somogyi R, Adryan KM, Ip NY, Zhu Y, Lindsay RM, DiStefano PS. Retrograde axonal transport of LIF is increased by peripheral nerve injury: correlation with increased LIF expression in distal nerve. Neuron. 1994; 12:191-204. [PubMed: 7507340]

Davis S, Aldrich TH, Stahl N, Pan L, Taga T, Kishimoto T, Ip NY, Yancopoulos GD. LIFR $\beta$ and gp130 as heterodimerizing signal transducers of the tripartite CNTF receptor. Science. 1993; 260:1805-1808. [PubMed: 8390097]

DeChiara TM, Vejsada R, Poueymirou WT, Acheson A, Suri C, Conover JC, Friedman B, McClain J, Pan L, Stahl N, et al. Mice lacking the CNTF receptor, unlike mice lacking CNTF, exhibit profound motor neuron deficits at birth. Cell. 1995; 83:313-322. [PubMed: 7585948]

Delcroix JD, Valletta JS, Wu C, Hunt SJ, Kowal AS, Mobley WC. NGF signaling in sensory neurons: evidence that early endosomes carry NGF retrograde signals. Neuron. 2003; 39:69-84. [PubMed: 12848933]

Dittrich E, Renfrew Haft C, Muys L, Heinrich PC, Graeve L. A di-leucine motif and an upstream serine in the interleukin (IL-6) signal transducer gp130 mediate ligand-induced endocytosis and down-regulation of the IL-6 receptor. J Biol Chem. 1996; 271:5487-5494. [PubMed: 8621406]

Fann MJ, Patterson PH. Neuropoietic cytokines and activin A differentially regulate the phenotype of cultured sympathetic neurons. Proc Natl Acad Sci USA. 1994; 91:43-47. [PubMed: 7904069]

Gearing D, Comeau M, Friend D, Gimpel S, Thut C, McGourty J, Brasher K, Ring J, Gillis S, Mosley B, Ziegler S, Cosman D. The IL-6 signal transducer, gp130: an oncostatin M receptor and affinity converter for the LIF receptor. Science. 1992; 255:1434-1437. [PubMed: 1542794]

Gibson RM, Laszlo GS, Nathanson NM. Calmodulin-dependent protein kinases phosphorylate gp130 at the serine-base dileucine internalization motif. Biochimica et Biophysica Acta -Biomembranes. 2005; 1714:56-62.

Gibson RM, Schiemann WP, Pritchard LB, Reno JM, Ericsson LH, Nathanson NM. Phosphorylation of human gp130 at Ser782 adjacent to the di-leucine internalization motif: Effects on expression and signaling. J Biol Chem. 2000; 275:22574-22582. [PubMed: 10811661]

Gurney ME, Yamamoto H, Kwon Y. Induction of motor neuron sprouting in vivo by ciliary neurotrophic factor and fasic fibroblast growth factor. J Neurosci. 1992; 12:3241-3245. [PubMed: 1494954]

Ha J, Lo KW, Myers KR, Carr TM, Humsi MK, Rasoul BA, Segal RA, Pfister KK. A neuron-specific cytoplasmic dynein isoform preferentially transports TrkB signaling endosomes. J Cell Biol. 2008; 181:1027-1039. [PubMed: 18559670]

Haan C, Kreis S, Margue C, Behrmann I. Jaks and cytokine receptors--an intimate relationship. Biochem Pharmacol. 2006; 72:1538-1546. [PubMed: 16750817]

Heerssen HM, Pazyra MF, Segal RA. Dynein motors transport activated Trks to promote survival of target-dependent neurons. Nat Neurosci. 2004; 7:596-604. [PubMed: 15122257]

Hendry IA, Murphy M, Hilton DJ, Nicola NA, Bartlett PF. Binding and retrograde transport of leukemia inhibitory factor by the sensory nervous system. J Neurosci. 1992; 12:3427-3434. [PubMed: 1527587]

Howe CL, Mobley WC. Long-distance retrograde neurotrophic signaling. Curr Opin Neurobiol. 2005; 15:40-48. [PubMed: 15721743]

Johnson JA, Nathanson NM. Differential requirements for p21ras and protein kinase C in the regulation of neuronal gene expression by NGF and neurokines. J Biol Chem. 1994; 269:1885618863. [PubMed: 8034640] 
Kato T, Sano M, Miyoshi S, Sato T, Hakuno D, Ishida H, Kinoshita-Nakazawa H, Fukuda K, Ogawa S. Calmodulin kinases II and IV and calcineurin are involved in leukemia inhibitory factorinduced cardiac hypertrophy in rats. Circ Res. 2000; 87:937-945. [PubMed: 11073891]

Kurek JB, Bower JJ, Romanella M, Koentgen F, Murphy M, Austin L. The role of leukemia inhibitory factor in skeletal muscle regeneration. Muscle and Nerve. 1997; 20:815-822. [PubMed: 9179153]

Kwon YW, Abbondanzo SJ, Stewart CL, Gurney ME. Leukemia inhibitory factor influences the timing of programmed synapses withdrawal from neonatal muscles. J Neurobiol. 1995; 28:35-50. [PubMed: 8586964]

Li M, Sendtner M, Smith A. Essential function of LIF receptor in motor neurons. Nature. 1995; 378:724-727. [PubMed: 7501019]

Linker RA, Maurer M, Gaupp S, Martini R, Holtmann B, Giess R, Rieckmann P, Lassmann H, Toyka $\mathrm{KV}$, Sendtner M, Gold R. CNTF is a major protective factor in demyelinating CNS disease: a neurotrophic cytokine as modulator in neuroinflammation. Nat Med. 2002; 8:620-624. [PubMed: 12042814]

Lucero HA, Robbins PW. Lipid rafts-protein association and the regulation of protein activity. Arch Biochem Biophys. 2004; 426:208-224. [PubMed: 15158671]

Nakashima K, Wiese S, Yanagisawa M, Arakawa H, Kimura N, Hisatsune T, Yoshida K, Kishimoto T, Sendtner M, Taga T. Developmental requirement of gp130 signaling in neuronal survival and astrocyte differentiation. J Neurosci. 1999; 19:5429-5434. [PubMed: 10377352]

O'Brien JJ, Nathanson NM. Retrograde activation of STAT3 by leukemia inhibitory factor in sympathetic neurons. J Neurochem. 2007; 103:288-302. [PubMed: 17608645]

Oppenheim RW, Prevette D, Qin-Wei Y, Collins F, MacDonald J. Control of embryonic motoneuron survival in vivo by ciliary neurotrophic factor. Science. 1991; 251:1616-1618. [PubMed: 2011743]

Parganas E, Wang D, Stravopodis D, Topham DJ, Marine JC, Teglund S, Vanin EF, Bodner S, Colamonici OR, van Deursen JM, Grosveld G, Ihle JN. Jak2 is essential for signaling through a variety of cytokine receptors. Cell. 1998; 93:385-395. [PubMed: 9590173]

Pike LJ. Lipid rafts: bringing order to chaos. J Lipid Res. 2003; 44:655-667. [PubMed: 12562849]

Port M, Gibson RM, Nathanson NM. Differential stimulation-induced receptor localization in lipid rafts for interleukin- 6 family cytokines signaling through the gp130/leukemia inhibitory factor receptor complex. J Neurochem. 2007; 101:782-793. [PubMed: 17448148]

Port MD, Laszlo GS, Nathanson NM. Transregulation of leukemia inhibitory factor receptor expression and function by growth factors in neuroblastoma cells. J Neurochem. 2008; 106:19411951. [PubMed: 18624908]

Radtke S, Wüller S, Yang XP, Lippok BE, Mütze B, Mais C, de Leur HS, Bode JG, Gaestel M, Heinrich PC, Behrmann I, Schaper F, Hermanns HM. Cross-regulation of cytokine signalling: proinflammatory cytokines restrict IL-6 signalling through receptor internalisation and degradation. J Cell Sci. 2010; 123:947-959. [PubMed: 20200229]

Rao MS, Tyrrell S, Landis SC, Patterson PH. Effects of ciliary neurotrophic factor (CNTF) and depolarization on neuropeptide expression in cultured sympathetic neurons. Dev Biol. 1992; 150:281-293. [PubMed: 1372570]

Rodig SJ, Meraz MA, White JM, Lampe PA, Riley JK, Arthur CD, King KL, Sheehan KC, Yin L, Pennica D, Johnson EM Jr, Schreiber RD. Disruption of the Jak1 gene demonstrates obligatory and nonredundant roles of the Jaks in cytokine-induced biologic responses. Cell. 1998; 93:373383. [PubMed: 9590172]

Saadat S, Sendtner M, Rohrer H. Ciliary neurotrophic factor induces cholinergic differentiation of rat sympathetic neurons in culture. J Cell Biol. 1989; 108:1807-1816. [PubMed: 2565906]

Schiemann WP, Graves LM, Baumann H, Morella KK, Gearing DP, Nielsen M, Krebs EG, Nathanson NM. Phosphorylation of the human leukemia inhibitory factor (LIF) receptor by MAP kinase and the regulation of the LIF receptor function by heterologous receptor activation. Proc Natl Acad Sci USA. 1995; 92:5361-5365. [PubMed: 7777512]

Sendtner M, Götz R, Holtmann B, Escary JL, Masu Y, Carroll P, Wolf E, Brem G, Brület P, Thoenen H. Cryptic physiological trophic support of motoneurons by LIF revealed by double gene targeting of CNTF and LIF. Curr Biol. 1996; 6:686-694. [PubMed: 8793295] 
Shimazaki T, Shingo T, Weiss S. The ciliary neurotrophic factor/leukemia inhibitory factor/gp130 receptor complex operates in the maintenance of mammalian forebrain neural stem cells. $\mathbf{J}$ Neurosci. 2001; 21:7642-7653. [PubMed: 11567054]

Siegel SG, Patton B, English AW. Ciliary neurotrophic factor is required for motoneuron sprouting. Exp Neurol. 2000; 166:205-212. [PubMed: 11085886]

Simons K, Ikonen E. Functional rafts in cell membranes. Nature. 1997; 387:569-572. [PubMed: 9177342]

Simons K, Toomre D. Lipid rafts and signal transduction. Nat Rev Mol Cell Biol. 2000; 1:31-39. [PubMed: 11413487]

Stahl N, Davis S, Wong V, Taga T, Koshimoto T, Ip NY, Yancopoulos GD. Cross-linking identifies leukemia inhibitory factor-binding protein as a ciliary neurotrophic factor receptor component. J Biol Chem. 1993; 268:7628-7631. [PubMed: 8385113]

Stahl N, Yancopoulos GD. The alphas, betas, and kinases of cytokine receptor complexes. Cell. 1993; 74:587-590. [PubMed: 8395346]

Stöckli KA, Lottspeich F, Sendtner M, Masiakowski P, Carroll P, Gotz R, Lindholm D, Thoenen H. Molecular cloning, expression and regional distribution of rat ciliary neurotrophic factor. Nature. 1989; 342:920-923. [PubMed: 2594085]

Taga T, Kishimoto T. Gp130 and interleukin-6 family of cytokines. Ann Rev Immunol. 1997; 15:797_ 819. [PubMed: 9143707]

Takahashi E, Fukuda K, Miyoshi S, Murata M, Kato T, Ita M, Tanabe T, Ogawa S. Leukemia inhibitory factor activates cardiac LType Ca2+ channels via phosphorylation of serine 1829 in the rabbit Cav1.2 subunit. Circ Res. 2004; 94:1242-1248. [PubMed: 15044319]

Trouillas M, Saucourt C, Guillotin B, Gauthereau X, Taupin JL, Moreau JF, Boeuf H. The LIF cytokine: towards adulthood. Eur Cytokine Netw 2009. 2009; 20:51-62.

Ure DR, Campenot RB. Leukemia inhibitory factor and nerve growth factor are retrogradely transported and processed by cultured rat sympathetic neurons. Dev Biol. 1994; 162:339-347. [PubMed: 7512056]

Ure DR, Campenot RB, Acheson A. Cholinergic differentiation of rat sympathetic neurons in culture: effects of factors applied to distal neurites. Dev Biol. 1992; 154:388-395. [PubMed: 1358731]

Wang X, Lupardus P, Laporte SL, Garcia KC. Structural biology of shared cytokine receptors. Ann Rev Immunol. 2009; 27:29-60. [PubMed: 18817510]

Ware CB, Horowitz MC, Renshaw BR, Hunt JS, Liggitt D, Koblar SA, Gliniak BC, Mckenna HJ, Papayannopoulou T, Thoma B, Cheng L, Donovan PJ, Peschon JJ, Bartlett PF, Willis CR, Wright BD, Carpenter MK, Davison BL, Gearing DP. Targeted disruption of the low-affinity leukemia inhibitory factor receptor gene causes placental, skeletal, neural and metabolic defects and results in perinatal death. Development. 1995; 121:1283-1299. [PubMed: 7789261]

Yamamori T, Fukada K, Aebersold R, Korsching S, Fann MJ, Patterson PH. The cholinergic neuronal differentiation factor from heart cells is identical to leukemia inhibitor factor. Science. 1989; 240:1412-1416. [PubMed: 2512641]

Yano H, Chao MV. Mechanisms of neurotrophin receptor vesicular transport. J Neurobiol. 2004; 58:244-257. [PubMed: 14704956]

Ye H, Kuruvilla R, Zweifel LS, Ginty DD. Evidence in support of signaling endosome-based retrograde survival of sympathetic neurons. Neuron. 2003; 39:57-68. [PubMed: 12848932] 


\section{HIGHLIGHTS}

- CNTF and LIF are cytokines that have a variety of effects on neural cells.

- CNTF and LIF use an overlapping site of receptor polypeptides.

- The functional receptors for LIF and CNTF are differentially localized in lipid rafts.

- The two signaling receptor subunits are differentially regulated by phosphorylation.

- Retrograde signaling by LIF and CNTF may be mediated by a signaling endosome mechanism. 